\title{
Co-Precipitation and magnetic properties of magnetite nanoparticles for potential biomedical applications
}

\begin{abstract}
Magnetite nanopowder was synthesized by co-deposition of iron salts in the presence of ethylenediaminetetraacetic acid (EDTA) using sodium hydroxide as a precipitating agent. The iron chloride underwent complex formation reaction with (EDTA) followed by coprecipitation of the iron complex by boiling to produce the magnetite powder. The prepared powders were investigated by high magnification SEM and XRD to identify the particle shape and size of the obtained magnetite nanoparticles and its chemical composition. It was observed that the produced magnetite powder has spherical like particle shape with $\sim 30 \mathrm{~nm}$ particle sizes and face centered cubic crystal structure. The magnetic properties of the obtained powder were measured using vibrating sample magnetometry (VSM). It was revaled that the obtained nanomagnetite particles have super magnetic character which of saturation magnetization $88.1 \mathrm{emu} / \mathrm{g}$ and squarness ratio of 0.14 which has the ability to used as a contrasting agent in magneto resonance imaging (MRI) diagnosis.
\end{abstract}

Keywords: Nanosized magnetite, Ethylene diaminetetra acetic acid (EDTA), Coprecipitation, Magnetic properties, Superparamagnetic materials
Volume 5 Issue 3 - 2017

\author{
Walid M Daoush, ${ }^{1,2}$ \\ 'Department of Production Technology, Helwan University, \\ Egypt \\ ${ }^{2}$ Department of Chemistry,Al-Imam Mohammad Ibn Saud \\ Islamic University, Saudi Arabia
}

\begin{abstract}
Correspondence: Walid M Daoush, Department of Production Technology, Helwan University, Egypt.Present Address: Department of Chemistry, Faculty of Science, Al-Imam Mohammad Ibn Saud Islamic University, Al Riyadh, KSA, Saudi Arabia Email waliddaoush@techedu.helwan.edu.eg
\end{abstract}

Received: March 29, 2017 | Published: April 18, 2017
Abbreviations: EDTA, Ethylene Diaminetetra Acetic Acid; VSM, Vibrating Sample Magnetometry; MRI, Magneto Resonance Imaging; PEG, Polyethylene Glycol; PVA, Polyvinyl Alcohol; FCC, Face Centered Cubic

\section{Introduction}

Nowadays, preparations of stable nano-magnetic fluids are of renewed interest, due to its application in Hyperthermia, targeted drug delivery, cell separation and magnetic resonance imaging (MRI). Magnetic fluids, or ferro-fluids consist mainly of nanosized magnetic particles, typically magnetite $\left(\mathrm{Fe}_{3} \mathrm{O}_{4}\right)$ suspended in a liquid carrier. Most of these applications require a high quality control in the production of these magnetic nanoparticles to be nontoxic, chemically stable, and uniform in size, well dispersed under physiological conditions, insensitive to oxidation and agglomeration in the body fluids. The biocompatible magnetite nanoparticles are not toxic at all, and they can be accumulated in different tissues depending on the particle size, which can increase the contrast between the different organs in living systems.$^{1-3}$ These medical applications require super paramagnetic magnetite with particle sizes $\sim 20 \mathrm{~nm} .{ }^{4}$ The efficacy, as MRI contrast agents, of magnetite nanoparticles depends to a large extent on their physicochemical properties, particularly their size and surface chemistry .5

But one property of being sensitive to oxidation and agglomeration has lemmatized its use. The solution to this problem is, to protect the magnetic nano particles by various types of coatings and stabilizers. Various coatings have been developed using biocompatible molecules such as dextran, polyethylene glycol (PEG), polyvinyl alcohol (PVA) and phospholipids. Recently coatings with dendrimers and silica have also been designed ${ }^{6}$

Magnetite $\left(\mathrm{Fe}_{3} \mathrm{O}_{4}\right)$ is a common magnetic iron oxide, and it has a cubic inverse spinel structure with oxygen forming a FCC closed packing and $\mathrm{Fe}$ cations occupying the interstitial tetrahedral sites and octahedral sites . ${ }^{7}$ The electrons can hop between $\mathrm{Fe}^{2+}$ and $\mathrm{Fe}^{3+}$ ions in the octahedral sites at room temperature, rendering magnetite an important part of half-metallic materials. ${ }^{8}$ Magnetite nanoparticles have been widely studied because of their applications in ultrahigh density magnetic storage media .' biological labeling, tracking, imaging, detection, and separations.${ }^{10}$ and ferrofluid.$^{11}$ Some of the physical and magnetic properties of magnetite are summarized in Table 1.

Hyperthermia is a promising therapeutic method in the cancer healing. The super paramagnetic particles can heat the surrounding area if an alternating (AC) magnetic field is used. If the used frequency is properly chosen, the nanoparticles can be induced only without affecting the iron content of the hemoglobin in the blood. One of the key points of the therapeutic use of hyperthermia is to selectively transport enough magnetic particles to the intended target tissue to generate enough heat locally by exposure to a tolerable level of magnetic fluid that does not in itself cause any undesirable side effects . ${ }^{12,13}$

Table 1 the properties of magnetite.${ }^{14}$ The super paramagnetic magnetite can be incorporated into embolic materials to enable MRI detection and thus find a practical application in embolotherapy. In this respect, magnetite nanoparticles are required to be water-soluble, monodisperse, super paramagnetic and easily to produce in large scale. It has been demonstrated that the physical and chemical properties of magnetite nanoparticles greatly depend upon the synthesis route.$^{15}$ and the synthesis of magnetite particles that can meet all above mentioned requirements remains a challenge. The magnetite can be synthesized by various methods, including: thermal decomposition and coprecipitation. The thermal decomposition route relies on the pyrolysis of organic precursors of iron, such as $\mathrm{Fe}(\mathrm{CO})_{5} .{ }^{16,17}$ and $\mathrm{Fe}(\mathrm{acac})_{3}{ }^{18,19}$ Recently, synthesis of magnetite by thermal decomposition of $\left[\mathrm{Fe}\left(\mathrm{CON}_{2} \mathrm{H}_{4}\right)_{6}\right]\left(\mathrm{NO}_{3}\right)_{3} .{ }^{20}$ was reported. Co-precipitations based on the hydrolysis of a mixture of $\mathrm{Fe}^{2+}$ and $\mathrm{Fe}^{3+}$ ions are used to fix the molar ratio in the inverse spinel structure. ${ }^{21}$ In this method, $\mathrm{Fe}^{2+}$ and $\mathrm{Fe}^{3+}$ ions are generally precipitated in alkaline solutions, such as ammonium hydroxide, potassium hydroxide or sodium hydroxide. In most cases, the syntheses are performed at $70-80^{\circ} \mathrm{C}$ or higher temperatures.$^{22}$ 
Table I The properties of magnetite ${ }^{14}$

\begin{tabular}{ll}
\hline Property & Magnetite \\
\hline Molecular formula & $\mathrm{Fe}_{3} \mathrm{O}_{4}$ \\
Density $\left(\mathrm{g} / \mathrm{cm}^{3}\right)$ & 5.18 \\
Melting point $\left({ }^{\circ} \mathrm{C}\right)$ & $1583-1597$ \\
Hardness & 5.5 \\
Magnetism (bulk) & Ferrimagnetic \\
Curie temperature $(\mathrm{K})$ & 850 \\
Ms at $300 \mathrm{~K}\left(\right.$ A.m $\left.{ }^{2} / \mathrm{kg}\right)$ & $92-100$ \\
Magnetism (nanoparticles) & Superparamagnetic \\
Standard free energy of & -1012.6 \\
formation $\Delta \mathrm{G}$ of $(\mathrm{kJ} / \mathrm{mol})$ & Cubic \\
Crystallographic structure & Inverse spinel \\
Molecular structure & $\mathrm{Fd} 3 \mathrm{~m}$ \\
Space point group & $\mathrm{a}=0.8396$ \\
Lattice parameters $(\mathrm{nm})$ &
\end{tabular}

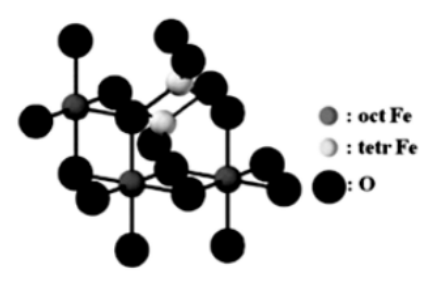

The main aim of the presence work was to prepare well stabilized magnetite nanoparticles using ethylene di amine tetra acetic acid (EDTA) as stabilizers to protect the particles from the aggregation under application conditions. Magnetite nanoparticles of size $\sim 30 \mathrm{~nm}$ are successfully synthesized via thermal decomposition method using iron chloride salt and EDTA as starting materials. The present route is easy to control during the reaction processes with considering Fe (II)/Fe (III) molar ratio control and basic condition. It also studied the ability to control the overall size of produced nanoparticles in order to provide super paramagnetic properties, the relative value of size distribution, the ability to manage morphology, spherical shape which is the most preferable. The chemical composition, crystal structure size, particle size and shape and magnetic properties of the produced magnetite nanoparticles were carefully characterized by XRD, SEM and vibrating sample magnetometer (VSM).

\section{Experimental}

High pure chemicals of iron (II) chloride, iron (III) chloride, sodium hydroxide and Ethylene di amine tetra acetic acid (EDTA) are purchased from El Naser Chemical Ltd; Egypt. Distilled water is also used for preparation of the solutions. An aqueous solution of $\mathrm{Fe}$ ions with a ratio of $\mathrm{Fe}(\mathrm{II}) / \mathrm{Fe}(\mathrm{III}) \sim 0.5$ was prepared by dissolving appropriate amounts of iron (II) chloride, iron (III) chloride distilled water as a source of iron under vigorous stirring of $500 \mathrm{rpm}$ at room temperature $\left(25^{\circ} \mathrm{C}\right)$. As a second step, solution contains EDTA was combined with the first solution and a homogenous mixture was formed by stirring. An aqueous colloidal solution of black particles dispersed in water was obtained just after adjusting the $\mathrm{pH}$ by sodium hydroxide and boiling of the contents. The obtained Black particles were washed free of anions with deionized water. Then the colloidal solution was washed by distilled water for several times until it is neutral. The obtained colloidal solution was filtered and dries.

Scanning electron microscopy of the model (JEOL, JSM-T20) was used for investigating shape and size of the prepared powder. The phase structures of magnetite nanoparticles were characterized by powder X-ray diffraction using (BRUKER D8 ADVANCE) at room temperature. The XRD data were collected between $10^{\circ}<2 \theta$ $<80^{\circ}$ using the $\mathrm{Cu}-\mathrm{K}_{\alpha}$ radiation filtered by Ni. The magnetization loops for obtained magnetite nanoparticles were measured at room temperature using a vibrating sample magnetometer of model VSM 9600-1 LDJ. The measured magnetic properties included saturation magnetization, retentivity, coercivity and squareness. Because the magnetization saturation and the retentivity changes with weight and volume of the sample, the results were divided on sample's weight. Magnetization versus applied field was measured at room temperature for all samples. The magnetometer was calibrated with standard nickel sphere. Analyses were carried out using a maximum applied field of 1.5 Tesla.

\section{Results and discussion}

\section{Synthesis of nanoparticles}

Co-precipitation is a facile and convenient way to synthesize magnetic nanoparticles from aqueous salt solutions by the addition of a base as a precipitating agent at room temperature or at elevated temperature. The main advantage of the precipitation process is that a large amount of nanoparticles can be synthesized. However, the control of particle size distribution is limited, because only kinetic factors are controlling the growth of the crystal. Nanoparticles of $\mathrm{Fe}_{3} \mathrm{O}_{4}$ were synthesized by hydrolysis of an aqueous solution containing iron salts and a base at room temperature in ambient atmosphere. $\mathrm{Fe}_{3} \mathrm{O}_{4}$ magnetic nanoparticles were prepared on the basis of co-precipitation $\mathrm{Fe}_{2+}$ and $\mathrm{Fe}_{3+}$ with a ratio of 1:1.

In this study, Ethylene di amine tetra acetic acid (EDTA) was used as stabilizing agent to allow more particles to escape the aggregation process and generally lowering the mean particle size. It is well known that $\mathrm{Fe}(\mathrm{OH})_{2}$ and $\mathrm{Fe}(\mathrm{OH})_{3}$ formed at $\mathrm{pH} \sim 8$ by the hydroxylation of the ferrous and ferric ions. When $(\mathrm{NaOH})$ was used as precipitating agent, a precipitate was immediately produced. Consequently, the formation of $\mathrm{Fe}_{3} \mathrm{O}_{4}$ nanoparticles occurred with black precipitation. The reaction is fast, with a high yielding and magnetite crystals are seen instantaneously after addition of precipitating agent of iron from its salt. The possible reaction for the formation of $\mathrm{Fe}_{3} \mathrm{O}_{4}$ nanoparticles is as follows:

$$
\begin{gathered}
\mathrm{Fe}^{3+}+3 \mathrm{OH}^{-} \rightarrow \mathrm{Fe}(\mathrm{OH})_{3} \\
\mathrm{Fe}(\mathrm{OH})_{3} \rightarrow \mathrm{FeOOH}+\mathrm{H}_{2} \mathrm{O} \\
\mathrm{Fe}^{2+}+2 \mathrm{OH}^{-} \rightarrow \mathrm{Fe}(\mathrm{OH})_{2} \\
2 \mathrm{FeOOH}+\mathrm{Fe}(\mathrm{OH})_{2} \rightarrow \mathrm{Fe}_{3} \mathrm{O}_{4} \downarrow+2 \mathrm{H}_{2}
\end{gathered}
$$

\section{Phase identification and particle morphology}

Figure 1 shows the XRD patterns of the obtained magnetite nanoparticles. It was observed that there is only one physical phase due to the presence of magnetite. In addition, there is no any other diffraction peaks corresponding to ferric chloride or other iron oxide, such as $\mathrm{Fe}_{2} \mathrm{O}_{3}$, was detected. This reveals that the resultant particles are mainly pure $\mathrm{Fe}_{3} \mathrm{O}_{4}$ of the face-centered cubic (FCC) crystal structure.

Figure 1 XRD pattern for the synthesized magnetite powder by co-precipitation from $\left(\mathrm{FeCl}_{2} / \mathrm{FeCl}_{3}\right)$ EDTA stabilized solution using sodium hydroxide as precipitating agent. Figure 2 illustrate the SEM micrograph for the produced magnetite powder. SEM images show that the samples consist of particles with a nearly spherical shape. They are approximately $30 \mathrm{~nm}$ in size, indicating that homogeneous magnetite nanoparticles can be synthesized. The magnetite particles are less agglomerated. It may be due to the formation of monolayer coverage of magnetite was reached in the presence of Ethylene di 
aminetetra acetic acid (EDTA) by coordinating-FeOH sites via one or two of their carboxylate functionalities through a water bridge with an outer sphere chemisorptions complexation. It is a good agreement with previous reports related to the addition of citrate ions in the coprecipitation solution of Massart process allowed for a decrease in the diameter of citrate-coated nanoparticles from 8 to $3 \mathrm{~nm} .{ }^{23-25}$

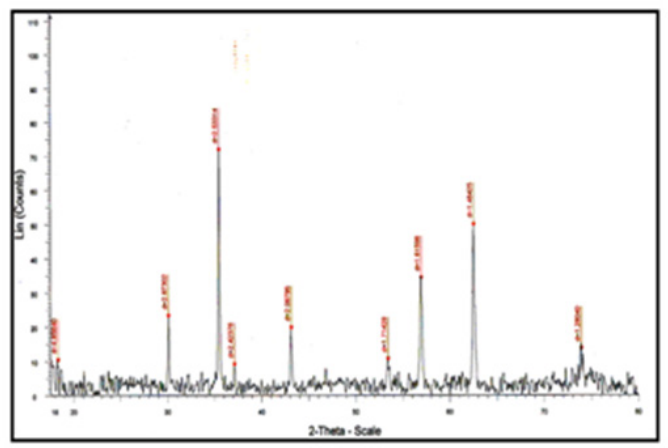

Figure I XRD pattern for the synthesized magnetite powder by coprecipitation from $\left(\mathrm{FeCl}_{2} / \mathrm{FeCl}_{3}\right)$ EDTA stabilized solution using sodium hydroxide as precipitating agent.
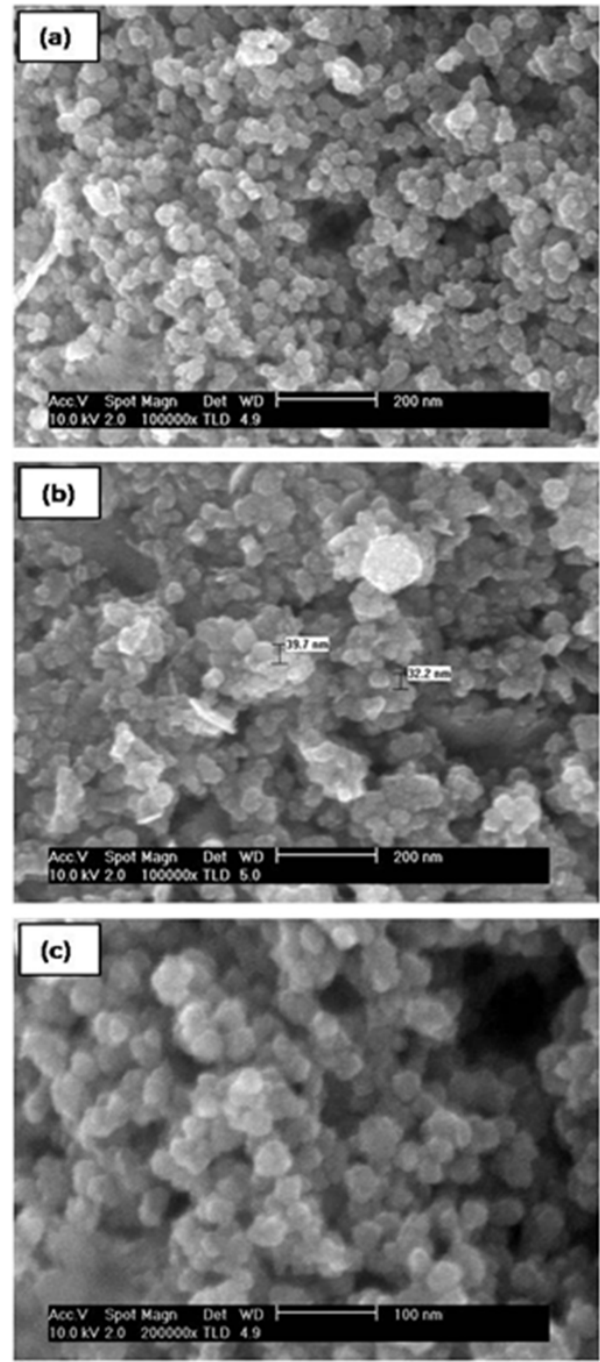

Figure 2 SEM images with different magnifications show the particle shape and size distribution for the synthesized magnetite powder by co-precipitation from $\left(\mathrm{FeCl}_{2} / \mathrm{FeCl}_{3}\right)$ EDTA stabilized solution using sodium hydroxide as precipitating agent.

\section{Magnetic Properties}

The iron atom has a strong magnetic moment due to four unpaired electrons in its $3 \mathrm{~d}$ orbitals. When crystals are formed from iron atoms, different magnetic states can arise. In a bulk ferromagnetic material, the magnetization $\mathrm{M}$ is the vector sum of all the magnetic moments of the atoms in the material per unit volume of the material. The magnitude of $\mathrm{M}$ is generally less than its value when all atomic moments are perfectly aligned, because the bulk material consists of domains with each domain having its own magnetization vector arising from an alignment of atomic magnetic moments within the domain. The magnetization vectors of all the domains in the material may not be aligned, leading to a decrease in the overall magnetization. When the length scale of the material becomes small (nanoscale), however, the number of domains decreases until there is a single domain when the characteristic size of the material is below some critical size. If an external magnetic field of strength $\mathrm{H}$ is applied to a ferromagnetic of magnetic strength $\mathrm{M}$, the magnetization curve of Figure 3 is obtained showing that $\mathrm{M}$ increases with $\mathrm{H}$ until a saturation value $\mathrm{M}_{\mathrm{S}}$ is reached. The magnetization curve displays a hysteresis loop, because all domains do not return to their original orientations when $\mathrm{H}$ is decreased after the saturation magnetization value is attained. Thus, when $\mathrm{H}$ returns to zero, there is a remnant magnetization $M_{r}$ which can only be removed by applying a coercive field $\mathrm{Hc}$ in the opposite direction to the initially applied field. A single domain magnetic material has no hysteresis loop and is said to be super paramagnetic. Iron oxide nanoparticles smaller than about 20 $\mathrm{nm}$ often display super paramagnetic behavior at room temperature.

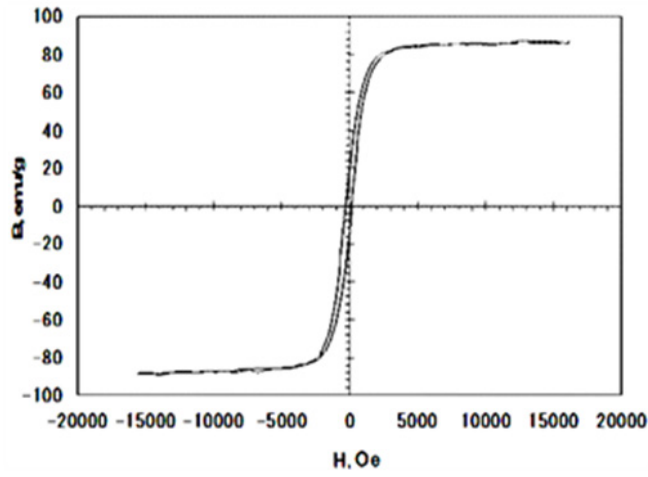

Figure 3 The $\mathrm{B}-\mathrm{H}$ Magnetic hysteresis curve for the synthesized $\mathrm{Fe}_{3} \mathrm{O}_{4}$ powder by co-precipitation from $\left(\mathrm{FeCl}_{2} / \mathrm{FeCl}_{3}\right)$ EDTA stabilized solution.

The B-H Magnetic hysteresis curve for the synthesized $\mathrm{Fe}_{3} \mathrm{O}_{4}$ powder by co-precipitation from $\left(\mathrm{FeCl}_{2} / \mathrm{FeCl}_{3}\right)$ EDTA stabilized solution (Figure 3). The magnetic properties were measured by using vibrating sample magnetometer. The hysteresis loops of the $\mathrm{Fe}_{3} \mathrm{O}_{4}$ nanoparticles measured at room temperature are illustrated in Figure 3 and the magnetic properties values were listed in Table 2. The magnetization curve for the synthesized magnetite nanoparticles reported show a very small hysteresis behavior for the samples and exhibits small values of coercivity field and remnant magnetization. This confirms that the synthesized particles exhibit super paramagnetic properties at room temperature. This is due to the magnetite nanoparticles exhibit super paramagnetic properties when they are smaller than the critical size of the magnetic domain size. ${ }^{26-}$ ${ }^{28}$ The nanosized magnetite samples display superparamagnetism and saturation magnetization $\left(\mathrm{M}_{\mathrm{s}}\right)$ values smaller than the bulk magnetite value, $92 \mathrm{emu} / \mathrm{g} .{ }^{14}$ The saturated magnetization values of $\mathrm{Fe}_{3} \mathrm{O}_{4}$ nanoparticles obtained at magnetic field of 1.5 Tesla was 88.1 $\mathrm{emu} / \mathrm{g}$. Several explanations have been provided on the decrease of the saturation magnetization with the reduction of the particle size of 
magnetite. One factor concerns the entity of the spin disorder layer, which increases with a decrease in crystallite size. Another factor for the reduction of the magnetic moment can be also explained through the effect of a dipolar interaction between magnetite nanoparticles. The irregular morphology of magnetite particles might influence the value of saturation magnetization as a contribution from surface anisotropy. As all the synthesized samples are almost spherical in shape, a zero contribution from surface anisotropy must be expected. A further reduction of Ms could be attributed to incomplete crystallization of magnetite after the reaction synthesis. The decrease in the saturation magnetization can be also due to changes in A and B site population. ${ }^{29-31}$

Table 2 Magnetic properties values were listed

\begin{tabular}{ll}
\hline Magnetic Properties & Value \\
\hline Saturation Magnetization $\left(\mathrm{B}_{\mathrm{s}}\right)$, emu/g & 88.1 \\
Retintivity $\left(\mathrm{B}_{\mathrm{r}}\right)$, emu/g & 12.65 \\
Coercivity $\left(\mathrm{H}_{\mathrm{c}}\right)$, Oe & 214 \\
Br/Bs Squarness ratio & 0.14 \\
\hline
\end{tabular}

Figure 3 shows that hysteresis disappeared with a little retentivity of $12.65 \mathrm{emu} / \mathrm{g}$ and coercirvity (Hc) of $214 \mathrm{Oe}$, indicating the absence as a long range magnetic dipole-dipole interaction among the assemblies of super paramagnetic nanoparticles. This means the prepared magnetite readily displayed magnetization when subjected to a magnetic field. It was found that there was a small retentivity of $12.65 \mathrm{emu} / \mathrm{g}$. One possible mechanism for this unique form is the independent thermal fluctuation of small ferromagnetic domains inside the particles. The boundaries of the small crystallites within the particles may contain lattice defects that impede the propagation of the magnetic order. In addition; for the produced magnetite nanoparticles of average diameter $<30 \mathrm{~nm}$ the retentivity and coercivity are very small so that producing a super paramagnetic behavior of magnetic nanoparticles. The values of retentivity and coercivity are shown almost zero. It was observed that the coercitivity $\mathrm{Hc}$ of the particles is near to zero within the experimental error. This value of $\mathrm{Hc}$ is within the (broad) range reported for nanostructured iron oxide nanoparticles. The retentivity to saturation ratio $\mathrm{R}=\mathrm{B} / \mathrm{B}_{\mathrm{s}}$ measured at 1.5 Tesla is 0.14 . Thus, the presented $R=0.14$ value suggests that the interparticle interactions are of antiferromagnetic nature.

Table 2 the magnetization saturation $\left(\mathrm{B}_{\mathrm{s}}\right)$, retentivity $\left(\mathrm{B}_{\mathrm{r}}\right)$, and the coercivity $\left(\mathrm{H}_{\mathrm{c}}\right)$ for the synthesized magnetite powder by thermal decomposition of $\left(\mathrm{FeCl}_{2} / \mathrm{FeCl}_{3}\right)$ EDTA complex solution.

\section{Conclusion}

A co-precipitation chemical synthesis route was used to produce magnetite nanoparticles redispersible in water. This study reveals that the produced magnetite nanoparticles have an average diameter $\sim 30 \mathrm{~nm}$ of a spherical particle shape. XRD showed the crystalline phase of iron oxide could correspond to face centered cubic magnetite $\left(\mathrm{Fe}_{3} \mathrm{O}_{4}\right)$ crystal structure. Measure of magnetization as a function of the field showed a superparamagnetism behavior in material because there were small coercitivity for the hysteresis cycles. The average diameter of the produced magnetite nanoparticles revealed to be ideal for in vitro studies and using in biological applications. The property of superparamagnetism determined by magnetometry allows the produced magnetite nanoparticles to be used in the monitoring and tracking by MRI technique, as well as in the Magneto Hyperthermia technique. We believe the synthesized magnetite nanoparticles have a potential for biomedical applications. Nonetheless, it is clear that both in vitro and in vivo studies are necessary to determine the applicability of this sample. Various tissues that could be expected to image with the produced magnetite nanoparticles due to its small size of $30 \mathrm{~nm}$ such as arteries, veins, capillaries and lung sacs.

\section{Acknowledgements}

The author thanks the XRD and VSM technician staff at the central metallurgical research and development institute (CMRDI) in Helwan, Cairo: Egypt for analyzing the chemical composition and measuring the magnetic properties of the synthesized samples. Also the author thanks the HRSEM technician staff at the Korean Advanced Institute of Science and Technology (KAIST) for their cooperation.

\section{Conflicts of interest}

None.

\section{References}

1. Portet D, Denizot B, Rump E et al. Nonpolymeric coatings of iron oxide colloids for biological use as magnetic resonance imaging contrast agents. J Colloid Interface Sci. 2001;238(1):37-42.

2. Wang YX, Hussain SM, Krestin GP Superparamagnetic iron oxide contrast agents: Physicochemical characteristics and applications in MR imaging. Eur Radiol. 2001;11(11):2319-2331.

3. Hu FQ, Wei L, Zhou Z et al. Preparation of biocompatible magnetite nanocrystals for in vivo magnetic resonance detection of cancer. $A d v$ Mater. 2006;18(19):2553-2556.

4. Sun S, Zeng H Size-controlled synthesis of magnetite nano-particies. $J$ Am Chem Soc. 2002;124(28):8204-8205.

5. Hongwei Duan, Min Kuang, Xiaoxia Wang et al. Reexamining the effects of particle size and surface chemistry on the magnetic properties of iron oxide nanocrystals: new insights into spin disorder and proton relaxivity. J Phys Chem. 2008;112(22):8127-8131.

6. Vargas JM, Zysler RD Tailoring the size in colloidal iron oxide magnetic nanoparticles. Nanotechnology. 2005;16(9):1474-1476.

7. Cornell RM, Schwertmann U The iron oxides: structure, properties, reactions, occurrence, and uses/R.M. Cornell, U. Schwertmann. Iron oxides p. 1996;28-29.

8. Verwey EJW Electronic conduction of magnetite $\left(\mathrm{Fe}_{3} \mathrm{O}_{4}\right)$ and its transition point at a low temperature. Nature. 1939;144(3642):327-328.

9. Zeng H, Li J, Liu JP et al. Sun SH Exchange-coupled nanocomposite magnets by nanoparticle self-assembly. Nature. 2002;420(6914):395-398.

10. Rohde JU, In JH, Lim MH et al. Crystallographic and spectroscopic characterization of a nonheme $\mathrm{Fe}(\mathrm{IV})-\mathrm{O}$ complex. Science. 2003;299(5609):1024-1025.

11. Raj K, Moskowitz RJ Commercial application of ferrofluids. Journal of Magnetism and Magnetic Materials. 1990;85(1-3):233-245.

12. Jordan A, Scholz R, Maie-rhauff K et al. Presentation of a new magnetic field therapy system for the treatment of human solid tumors with magnetic fluid hyperthermia. J Magn Magn Mater. 2001;22:5118-5126.

13. Song H, Choi J, Huh Y et al. Surface modulation of magneticnanocrystals in the development of highly efficient magnetic resonance probes for intracellularlabeling. J Am Chem Soc. 2005;127(28):9992-9993.

14. Cornell RM, Schwertmann U The Iron Oxides: Structure, Properties, Reactions, Occurrences and Uses. ( $2^{\text {nd }}$ edn), Wiley VCH Weinheim, Germany. 2004

15. Dawei Hu, Yanmin Wang, Qi Song Weakly magnetic field-assisted synthesis of magnetite nanoparticles in oxidative co-precipitation. Particuology. 2009;7:363-367. 
16. Peng S, Wang C, Xie J, Sun S Synthesis and stabilization of monodisperse Fe nanoparticles. J Am Chem Soc. 2006;128(33):10676-10677.

17. Ge J, Hu Y, Biasini M et al. One-step synthesis of highly water-soluble magnetite colloidal nanocrystals. Chem Eur J. 2007;13(25):7153-7161.

18. Lu X, Niu M, Qiao R, Gao M Superdispersible PVP-coated $\mathrm{Fe}_{3} \mathrm{O}_{4}$ nanocrystalsprepared by a "one-pot" reaction. J Phys Chem B. 2008;112(46):14390-14394.

19. Zhen $\mathrm{Li}$, Hui Chen, Haobo Bao $\mathrm{H}$ et al. One-pot reaction to synthesize water-soluble magnetite nanocrystals. Chem. Mater 2004;16(8):1391-1393.

20. Zhao S, Asuha S One-pot synthesis of magnetite nanopowder and their magnetic properties. Powder Technol. 2010;197:295-297.

21. Bandhu A, Mukherjee S, Acharya S, Modak S, Brahma SK, et al. (2009) Dynamic magnetic behavior and Mössbauer effect measurements of magnetite nanoparticles prepared by a new technique in the coprecipitation method. Solid State Commun 149: 1790-1794.

22. Ozkaya T, Toprak MS, Baykal A et al.Synthesis of $\mathrm{Fe}_{3} \mathrm{O}_{4}$ nanoparticles at $100^{\circ} \mathrm{C}$ and its magnetic characterization. $J$ Alloys Compd. 2009;472:18-23.

23. Massart $\mathrm{R}$ Preparation of aqueous magnetic liquids in alkaline and acidic media. IEEE Trans Magn. 1981;17(2):1247-1248.

24. Tartaj P, Morales MP, Veintemillas-Verdaguer S et al. The preparation of magnetic nanoparticles for applications in biomedicine. J Phys D: Appl Phys. 2006;36(2003):R182-R197
25. Wanquan Jiang, Yang HC, Yang SY et al. Preparation and properties of super-paramagnetic nanoparticles with narrow size distribution and biocompatible. J Magn Magn Mater. 2004;283:210-214.

26. Goya GF, Berquó TS, Fonseca FC et al. Static and dynamic magnetic properties of spherical magnetite nanoparticles. $J$ Appl Phys. 2003;94(5):3520-3528.

27. Benyang Wang, Qifeng Wei, Shiliang Qu Synthesis and characterization of uniform and crystalline magnetite nanoparticles via oxidationprecipitation and modified co-precipitation methods. Int J Electrochem Sci. 2013;8(2013):3786-3793.

28. Mahmed N, Heczko O, Söderberg O et al. Room temperature synthesis of magnetite $\left(\mathrm{Fe}_{3} \mathrm{O}_{4}\right)$ nanoparticles by a simple reverse co-precipitation Method. IOP Conf Ser Mater Sci Eng. 2011;18:032020.

29. Morales MP, Andres-Verges M, Veintemillas-Verdaguer S et al. Structural effects on the magnetic properties of gamma-Fe2O3 nanoparticles. J Magn Magn Mater. 1999;203:146-148.

30. Bødker F, Mørup S, Linderoth S Surface effects in metallic lron nanoparticles. Phys Rev Lett. 1994;72(2):282-285.

31. Gerardo $\mathrm{F}$ Goya Magnetic dynamics of $\mathrm{Zn}^{57} \mathrm{Fe}_{2} \mathrm{O}_{4}$ nanoparticles dispersed in a ZnO matrix. IEEE Trans Magn. 2002;38(5):2610-2612. 